\title{
Organoclay-Based Formulations to Reduce the Environmental Impact of the Herbicide Diuron in Olive Groves
}

\author{
C. Trigo \\ R. Celis* \\ M. C. Hermosín \\ J. Cornejo \\ Instituto de Recursos Naturales \\ y Agrobiología de Sevilla (IRNAS) \\ CSIC \\ Avenida Reina Mercedes 10 \\ P.O. Box 1052 \\ 41080 Sevilla, Spain
}

\begin{abstract}
Ground and surface water contamination caused by undesirable transport losses of herbicides commonly applied to olive (Olea Europaea) groves in Spain and other Mediterranean countries is demanding strategies to reduce the environmental impact of such herbicides. In this work, organoclay-based formulations of a herbicide widely applied to olive groves, diuron [3-(3,4-dichlorophenyl)-1,1-dimethyl urea], were prepared by preadsorbing the herbicide on three organoclays. Then, the ability of the organoclay-based formulations to reduce the herbicide release rate and leaching potential in two soils as compared to a standard commercial formulation of the herbicide was assessed. The organoclays were obtained by treating Wyoming montmorillonite (SWy-2) and Arizona montmorillonite (SAz-1) with an amount of spermine (SPERM) or hexadecyltrimethylammonium (HDTMA) cations equal to $100 \%$ of the cation exchange capacity of the montmorillonites. Batch release and column leaching tests indicated that the organoclay-based formulations of diuron made the release of the herbicide slower and reduced its leaching potential in soils, as compared with a standard commercial formulation containing the herbicide in a readily available form. Soil incubation experiments revealed that the persistence of the herbicide applied to soil as organoclay-based formulations was only slightly prolonged compared with the herbicide applied in a readily available form, and that most herbicide in the formulations was ultimately available for degradation. The use of organoclaybased formulations is proposed as a strategy to reduce extensive transport losses associated with the application of diuron in high-risk scenarios, such as Mediterranean olive groves.
\end{abstract}

$\mathrm{G}$ round and surface water contamination by herbicides used In olive groves in Spain and other Mediterranean countries has become a serious issue. In Spain, several cases of contamination of drinking water bodies by such herbicides have occurred in the last few years, affecting the drinking water supply of many towns and greatly increasing the water purification costs. This has led authorities to prohibit or restrict the application of widely used active ingredients, such as simazine, diuron, terbuthylazine, or MCPA (Santiago-Mora et al., 2005). In olive groves, soil texture, pronounced slopes, and climatic conditions favor losses of the applied herbicides by leaching and runoff processes (Celis et al., 2007). To compensate for such losses, herbicides need to be applied in concentrations exceeding those strictly required for weed control, and the number of applications needs often to be increased. The excessive quantities of herbicide added increase the risk of surface and ground water pollution. In this context, there is a need to develop strategies directed to preventing water

Soil Sci. Soc. Am. J. 73:1652-1657

doi:10.2136/sssaj2008.0349

Received 30 Oct. 2008.

*Corresponding author (rcelis@irnase.csic.es).

(c) Soil Science Society of America

677 S. Segoe Rd. Madison WI 53711 USA

All rights reserved. No part of this periodical may be reproduced or transmitted in any form or by any means, electronic or mechanical, including photocopying, recording, or any information storage and retrieval system, without permission in writing from the publisher. Permission for printing and for reprinting the material contained herein has been obtained by the publisher. pollution by herbicides applied to olive groves, particularly in highrisk scenarios such as Mediterranean areas (Celis et al., 2007).

The use of slow release formulations has been proposed as an efficient strategy to reduce the environmental impact of soil-applied pesticides. Beneficial effects related to the use of slow release formulations include reduced mobility of the active ingredient, reduction in the amount of chemical required for pest control, savings in manpower and energy by reducing the number of applications required in comparison with conventional formulations, increased safety for the pesticide applicator, and a general decrease in nontarget effects (Gerstl et al., 1998). Organoclays, that is, natural clay minerals with their original inorganic exchange cations replaced with organic cations, have been proven to be very good adsorbents for different classes of pesticides and, accordingly, have been proposed as carriers for the design of slow release formulations of pesticides (El-Nahhal et al., 2001; Hermosín et al., 2001; Prost and Yaron, 2001; Lagaly, 2001; Carrizosa et al., 2003; Cornejo et al., 2008). The organic cations most commonly used for the preparation of organoclays are synthetic, quaternary ammonium ions of the general form $\left[\left(\mathrm{CH}_{3}\right)_{3} \mathrm{NR}\right]^{+}$or $\left[\left(\mathrm{CH}_{3}\right)_{2} \mathrm{NR}_{2}\right]^{+}$, where $\mathrm{R}$ is an aromatic or aliphatic hydrocarbon (Jaynes and Boyd, 1991). Nevertheless, the modification of clay minerals with naturally occurring organic cations has recently been pointed out as particularly interesting to reduce concern about the incorporation of these materials into soil and aquatic environments for practical applications (Cruz-Guzmán et al., 2004, 2005).

In this work, batch, incubation, and column leaching experiments were designed to assess the behavior in soil of organoclaybased formulations of a herbicide widely applied to olive groves: 


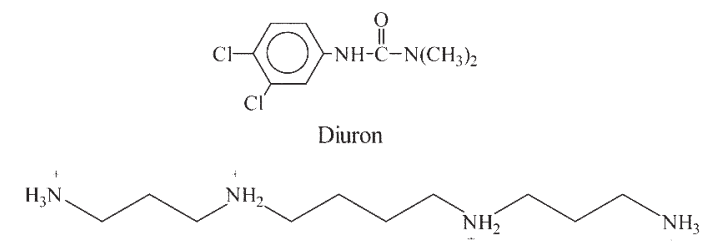

Spermine (SPERM)

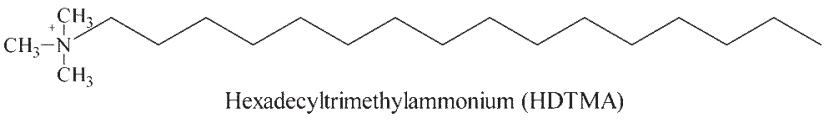

Fig. 1. Molecular structures of diuron, spermine, and hexadecyltrimethylammonium.

diuron. In a previous paper, a number of organoclays prepared by modification of two montmorillonites (SWy-2 and SAz-1) with different natural and synthetic organic cations were tested as adsorbents of diuron (Celis et al., 2007). Spermine (SPERM) and HDTMA cations were found to be those providing the montmorillonites with the highest affinity for this herbicide. Here, SPERM- and HDTMA-montmorillonites were selected to prepare organoclay-based formulations of diuron, comparing their release, persistence and leaching behavior with that of a reference standard commercial formulation containing the herbicide in a readily available form. Two soils from southern Spain were selected for the study, as representatives of those typically used for olive growing in Mediterranean areas. Previous research has shown that the type of formulation can strongly influence the release and leaching behavior of the herbicide diuron in soils (Cotterill et al., 1996; Fernández-Pérez et al., 1999; Chaplain et al., 2001).

\section{MATERIALS AND METHODS Herbicide and Soils}

Diuron [3-(3,4-dichlorophenyl)-1,1-dimethyl urea] (Fig. 1) is a phenylurea herbicide widely used for selective weed control in crops such as olive groves, asparagus, citrus, cotton, pineapple, sugarcane, etc. at 0.6 to $4.8 \mathrm{~kg} \mathrm{ha}^{-1}$ (Worthing and Hance, 1991). It has molecular weight $233.1 \mathrm{~g} \mathrm{~mol}^{-1}$ and water solubility about $42 \mathrm{mg} \mathrm{L}^{-1}$ at $27^{\circ} \mathrm{C}$ (Worthing and Hance, 1991). Pure analytical diuron (purity > 98\%) from Sigma-Aldrich (Spain) was used to prepare the external standards for herbicide analysis, the initial herbicide solutions used in adsorption-desorption experiments, and the organoclay-based formulations of the herbicide. Commercial diuron (Diuron 80 WDG, 80\% waterdispersible granules) from Comercial Química Massó S.A. (Spain) was used as a reference standard formulation in the release, incubation, and column leaching experiments.

The two soils used in the incubation and column leaching tests were sampled from experimental olive fields located in Seville (Spain). The soils were sampled from the top 0 - to 20 -cm layer, airdried, and sieved $(2 \mathrm{~mm})$ before use. The main physicochemical characteristics of the soils are summarized in Table 1. Soil texture was determined by the hydrometer method, whereas the organic $\mathrm{C}$ and carbonate contents were determined by dichromate oxidation and by the pressure calcimeter method, respectively. The $\mathrm{pH}$ of the soils was measured in a $1: 2(\mathrm{w} / \mathrm{w})$ soil/deionized water suspension.
Table 1. Physicochemical characteristics of the soils used.

Soil texture Sand Silt Clay $\mathrm{CaCO}_{3}$ Organic C $\mathrm{pH}$

\begin{tabular}{|c|c|c|c|c|c|c|c|}
\hline \multirow[b]{2}{*}{ Soil 1} & \multirow[b]{2}{*}{ Sandy clay loam } & \multicolumn{5}{|c|}{$\%$} & \multirow[b]{2}{*}{8.5} \\
\hline & & 63 & 16 & 21 & 16.9 & 1.39 & \\
\hline Soil 2 & Sandy loam & 83 & 7 & 10 & 6.5 & 0.71 & 8.4 \\
\hline
\end{tabular}

\section{Organoclays and Organoclay-based Formulations of Diuron}

The organoclays used in this work (SW-SPERM, SW-HDTMA, and SA-HDTMA) were selected on the basis of a previous study that indicated their potential suitability for the preparation of slow release formulations of diuron (Celis et al., 2007). For the preparation of the organoclays, SWy-2 Na-rich Wyoming montmorillonite and SAz1 Ca-rich Arizona montmorillonite from The Clay Minerals Society (Purdue University) were modified with HDTMA or SPERM cations (Sigma-Aldrich, Spain) (Fig. 1) through ion-exchange reactions, as described in Celis et al. (2007). Briefly, solutions containing an amount of organic cation corresponding to $100 \%$ of the cation exchange capacity of the montmorillonites were added to $1 \mathrm{~g}$ of SWy-2 or SAz-1. The suspensions were shaken for $24 \mathrm{~h}$, centrifuged, washed with distilled water, and then freeze-dried. Some characteristics of the organoclays are given in Table 2.

Organoclay-based formulations of diuron were prepared by preadsorbing the herbicide on the organoclays. For this purpose, $100 \mathrm{mg}$ of each organoclay (SW-SPERM, SW-HDTMA, or SA-HDTMA) were treated with $160 \mathrm{~mL}$ of an aqueous solution containing $40 \mathrm{mg} \mathrm{L}^{-1}$ of diuron. After treatment, the suspensions were shaken at $20 \pm 2^{\circ} \mathrm{C}$ for $24 \mathrm{~h}$, filtered (pore size $=0.45 \mu \mathrm{m}$ ), and the resultant solids were airdried and ground in an agate mortar. The recovery of solids was $>80 \%$. Preliminary experiments revealed that with this procedure the organoclays became saturated with the herbicide, so that no further adsorption could be achieved. The amount of diuron adsorbed on the organoclays was indirectly calculated by difference between the amount of herbicide added and the amount remaining in solution after filtration, and also by direct extraction (24 h end-over-end shaking) of $5 \mathrm{mg}$ of the organoclay-diuron complexes with $10 \mathrm{~mL}$ of methanol.

\section{Adsorption-Desorption Experiments}

Adsorption-desorption isotherms of diuron on the organoclays (SW-HDTMA, SW-SPERM, and SA-HDTMA) were obtained by the batch equilibration procedure. Duplicate $20 \mathrm{mg}$ adsorbent samples were equilibrated with $8 \mathrm{~mL}$ of herbicide initial solutions $\left(C_{\text {ini }}=0.1\right.$, $0.2,1$, and $2 \mathrm{mg} \mathrm{L}^{-1}$ ) by shaking mechanically at $20 \pm 2^{\circ} \mathrm{C}$ for $24 \mathrm{~h}$. After equilibration, the suspensions were centrifuged and $4 \mathrm{~mL}$ of the supernatant solutions were removed for analysis. The herbicide concentration in the supernatant solutions was determined by high performance liquid chromatography (HPLC) as described below. The amount of herbicide

\section{Table 2. Some characteristics of the organoclays.}

\begin{tabular}{lllcc} 
Organoclay & Montmorillonite & \multicolumn{1}{c}{ Organic cation } & OCtSt & $\mathbf{d}_{\mathbf{0 0 1}} \mathbf{\ddagger}$ \\
\hline & & & $-\%-$ & $-\AA-$ \\
SW-SPERM & SWy-2 & Spermine & 96 & 13.0 \\
SW-HDTMA & SWy-2 & Hexadecyltrimethylammonium & 93 & 18.0 \\
SA-HDTMA & SAz-1 & Hexadecyltrimethylammonium & 101 & 24.0 \\
\hline
\end{tabular}

+ Organic cation saturation: percentage of the cation exchange capacity of SWy-2 (76.4 $\mathrm{cmolc} \mathrm{kg}^{-1}$ ) or SAz-1 (120 cmolc $\mathrm{kg}^{-1}$ ) compensated by organic cations (calculated from the $\mathrm{N}$ content of the samples).

‡ Basal spacing values for air-dried oriented specimens. 
adsorbed was calculated from the difference between the initial and the equilibrium solution concentrations. Desorption was measured immediately after adsorption from the highest equilibrium point of the adsorption isotherm, that is, that corresponding to the initial concentration $2 \mathrm{mg} \mathrm{L}^{-1}$. The $4 \mathrm{~mL}$ of supernatant removed for the adsorption analysis were replaced with $4 \mathrm{~mL}$ of distilled water. After shaking at 20 $\pm 2^{\circ} \mathrm{C}$ for $24 \mathrm{~h}$, the suspensions were centrifuged, and the herbicide concentration was determined in the supernatant. This desorption procedure was repeated three times.

\section{Batch Release Kinetics}

Aliquots containing $0.5 \mathrm{mg}$ of diuron (active ingredient, a.i.), either as organoclay-based formulations or as the reference standard commercial formulation, were added to $250 \mathrm{~mL}$ of distilled water in glass bottles sealed with screw caps. At selected times $(0-144 \mathrm{~h})$, the bottles were handshaken, allowed to settle for $10 \mathrm{~min}$, and then $3 \mathrm{~mL}$ of the supernatant solution were removed, filtered, and analyzed by HPLC to determine the aqueous concentration of diuron. The expected herbicide concentration assuming complete release of diuron from the formulations was $2 \mathrm{mg} \mathrm{L}^{-1}$. The herbicide release kinetics was obtained in duplicate.

\section{Incubation Experiment}

The dissipation curves of diuron in the soils were obtained by means of an incubation experiment in which the soils $(600 \mathrm{~g})$ were spiked with diuron at a concentration of $1.7 \mathrm{mg} \mathrm{kg}^{-1}$ air-dried soil, following a spiking protocol based on that proposed by Brinch et al. (2002). Briefly, a subsample of $25 \%$ of the air-dried and sieved soil ( $150 \mathrm{~g}$ ) was wetted with $140 \mathrm{~mL}$ distilled water and then spiked with the herbicide $(1 \mathrm{mg}$ a.i.) either as organoclay-based formulations or as the reference standard commercial formulation. The spiked $150 \mathrm{~g}$-soil aliquot was thoroughly homogenized, and then the remaining $75 \%$ of the soil $(450 \mathrm{~g})$ was mixed with the spiked soil subsample by adding sequentially three portions of $150 \mathrm{~g}$ of unspiked soil. The spiked soils were incubated in glass jars at room temperature for $91 \mathrm{~d}$. The moisture content was maintained at a constant level (25\%) throughout the experiment by adding distilled water as necessary. The soils were sampled periodically and frozen until analyzed. Diuron was extracted by shaking $5 \mathrm{~g}$ of duplicate soil samples with $10 \mathrm{~mL}$ of methanol for $24 \mathrm{~h}$ and the extracts were analyzed by HPLC. A preliminary experiment showed that this extraction procedure recovered $>95 \%$ of the diuron freshly applied to the soils.

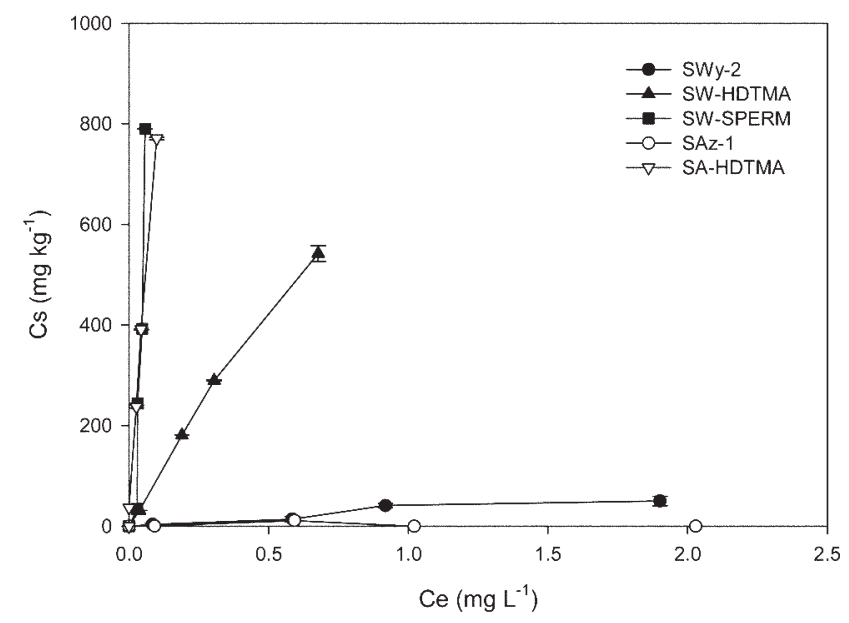

Fig. 2. Diuron adsorption isotherms on untreated clays (SWy-2 and SAz-1) and organoclays.

\section{Leaching Experiment}

Leaching was studied in $30 \mathrm{~cm}$ length $\times 3.1 \mathrm{~cm}$ internal diameter glass columns. The top $5 \mathrm{~cm}$ were filled with sea sand and the bottom $5 \mathrm{~cm}$ with sea sand plus glass wool, to prevent losses of soil during the experiment. The other $20 \mathrm{~cm}$ were hand packed with air-dried soil, then saturated with deionized water and allowed to drain for $24 \mathrm{~h}$. The calculated pore volume of the columns after saturation was $62.7 \pm 0.5 \mathrm{~mL}$ for Soil 1 and $58.5 \pm 0.5 \mathrm{~mL}$ for Soil 2 . The amount of diuron corresponding to an application rate of $2 \mathrm{~kg} \mathrm{ha}^{-1}(0.15 \mathrm{mg}$ a.i. $)$ was applied to the top of duplicate soil columns either as organoclay-based formulations or as the reference standard commercial formulation. To facilitate the application of the solids, $15 \mathrm{~mL}$ of water were used. Daily, $15 \mathrm{~mL}$ of deionized water were added to the top of the columns, the leachates were collected, and the concentration of diuron in the leachates was determined by HPLC. At the end of the leaching experiment (i.e., after $76 \mathrm{~d}$ for Soil 1 and 64 $\mathrm{d}$ for Soil 2), soil samples of approximately $40 \mathrm{~g}$ were taken from different depths of the columns (0- to 5-, 5- to 10-, 10- to 15-, and 15- to 20-cm depth) and extracted once with $100 \mathrm{~mL}$ of methanol by shaking mechanically at $20 \pm 2^{\circ} \mathrm{C}$ for $24 \mathrm{~h}$. The suspensions were centrifuged $(30 \mathrm{~min}$ at $3000 \times \mathrm{g})$, filtered, and analyzed by HPLC to determine the amount of diuron at different depths of the soil columns. All leaching experiments were conducted in triplicate.

\section{Analysis of Diuron}

Diuron was determined by HPLC using a Waters 600E chromatograph coupled to a Waters 996 diode-array detector. The following chromatographic conditions were used: Novapack C18 column $(150 \mathrm{~mm}$ length $\times 3.9 \mathrm{~mm}$ i.d.) (Waters), acetonitrile/water (40:60) eluent mixture at a flow rate of $1 \mathrm{~mL} \mathrm{~min}^{-1}, 25 \mu \mathrm{L}$ injection volume, and UV detector at 250 $\mathrm{nm}$. External calibration curves with standard solutions of diuron between 0.1 and $2 \mathrm{mg} \mathrm{L}^{-1}$ were used in the calculations.

\section{RESULTS AND DISCUSSION Organoclay-based Formulations of Diuron}

The organoclays, SW-SPERM, SW-HDTMA, and SAHDTMA, were selected on the basis of a previous study that revealed their high affinity for the herbicide diuron (Fig. 2) and the reversibility of the adsorption-desorption process. A detailed discussion of the adsorption-desorption of diuron by different organoclays, including those selected for the present study, can be found in Celis et al. (2007). Replacement of the original inorganic exchange cations of SWy-2 and SAz-1 by SPERM and HDTMA cations changes the nature of the montmorillonite surfaces from hydrophilic to hydrophobic, greatly increasing their affinity for diuron. Hydrogen bonding between the $\mathrm{C}=\mathrm{O}$ group of diuron and the $-\mathrm{NH}_{3}{ }^{+} /-\mathrm{NH}_{2}{ }^{+}$-groups of SPERM and hydrophobic interactions between the herbicide and the alkyl chains of both SPERM and HDTMA were proposed to explain the high affinity of diuron by these organoclays (Celis et al., 2007). In addition, the reversibility of the adsorption-desorption of diuron by these organoclays was pointed out as a particularly interesting property in terms of the potential use of the adsorbents as supports for the preparation of slow release formulations (Celis et al., 2007).

Organoclay-based formulations of diuron were prepared by preadsorbing the herbicide on the organoclays using a concentrated aqueous solution of the herbicide $\left(40 \mathrm{mg} \mathrm{L}^{-1}\right)$, as described in the Materials and Methods section. The amounts of diuron in the formulations calculated by difference between the amount 
Table 3. Herbicide content of the organoclay-based formulations of diuron as determined by indirect and direct methods.

\begin{tabular}{lcc}
\multirow{2}{*}{\multicolumn{1}{c}{ Formulation }} & \multicolumn{2}{c}{ Diuron content $(\%)$} \\
\cline { 2 - 3 } & Indirect method & Direct method \\
\hline SW-SPERM/Diuron & $1.66 \pm 0.0+$ & $1.43 \pm 0.01$ \\
SW-HDTMA/Diuron & $1.03 \pm 0.01$ & $0.92 \pm 0.02$ \\
SA-HDTMA/Diuron & $3.23 \pm 0.01$ & $2.82 \pm 0.03$ \\
\hline
\end{tabular}

† Mean \pm standard error.

of herbicide added and that not adsorbed by the organoclays were found to be similar to those calculated by direct extraction of the formulations with methanol (Table 3). Considering the amounts extractable with mild organic solvents, such as methanol, as estimates of potentially available herbicide (Hance et al., 1977; Cox and Walker, 1999; Barriuso et al., 2004), our results indicate that most diuron in the formulations is in a potentially available form. This is in contrast to previously proposed diuron formulations, in which a significant amount of herbicide tended to remain in formulation granules and was more resistant to release (Fernández-Pérez et al., 1999).

\section{Batch Release Kinetics}

The release kinetics of diuron into water from the organoclay-based formulations under static conditions is compared in Fig. 3 with the release pattern of diuron from the reference standard commercial formulation. In contrast to the standard commercial formulation, which released $100 \%$ of the herbicide almost instantaneously, the organoclay-based formulations of diuron displayed slow release properties in water. The initial amount of diuron released into water by the organoclays ranged between 9 and 24\%, whereas the final amount of diuron released $(t=144 \mathrm{~h})$ under the static conditions used in the experiment ranged between 42 and $83 \%$. The total amount of herbicide released at the end of the experiment was less for SA-HDTMA and SW-SPERM compared with SW-HDTMA, which is consistent with the different affinities of the organoclays for the herbicide observed in the batch adsorption study (Fig. 2). Because different rates and extents of diuron occurred depending on the type of organoclay, the possibility exists to select the most suitable organoclay to achieve the desired release behavior of diuron.

\section{Incubation Experiment}

Dissipation curves for diuron in two soils after application of the herbicide either as a standard commercial formulation or as complexes with the organoclays SW-SPERM and SA-HDTMA are shown in Fig. 4. The sigmoidal shape of the dissipation curves are typical of biodegradation of compounds utilized as microbial growth substrate (Kearney et al., 1997). According to Fig. 4, the half-life of diuron in the soils ranges between about 35 and $55 \mathrm{~d}$, depending on the soil and formulation type. These values are in accordance with those previously reported for the soil persistence of diuron (Worthing and Hance, 1991; Giacomazzi and Cochet, 2004).

In general, degradation of diuron in Soil 2 occurred faster than in Soil 1, despite Soil 2 contained less organic matter and presumably less microbial activity than Soil 1 . This result may be indicative of a greater bioavailability of the herbicide in the low organic matter, coarse textured soil (Soil 2). On the other hand, the effect of formulation on the persistence of diuron in the two soils was small. The persistence of the herbicide applied

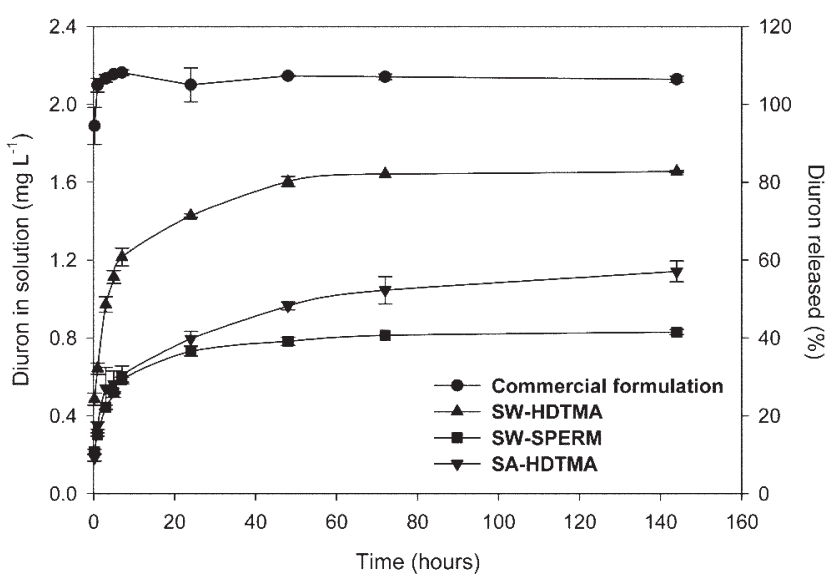

Fig. 3. Diuron release kinetics into water from the commercial and organoclay-based formulations.

as organoclay-based formulations was only slightly longer compared with the persistence of the herbicide applied in a readily available (commercial) form. It is also worthy to note that the residual amounts of diuron extracted at the end of the incubation experiment $(t=91 \mathrm{~d})$ were very low ( $<5 \%$ of the amount applied) and very similar for all formulations tested. This indicated that most herbicide in the formulations was ultimately available for degradation.
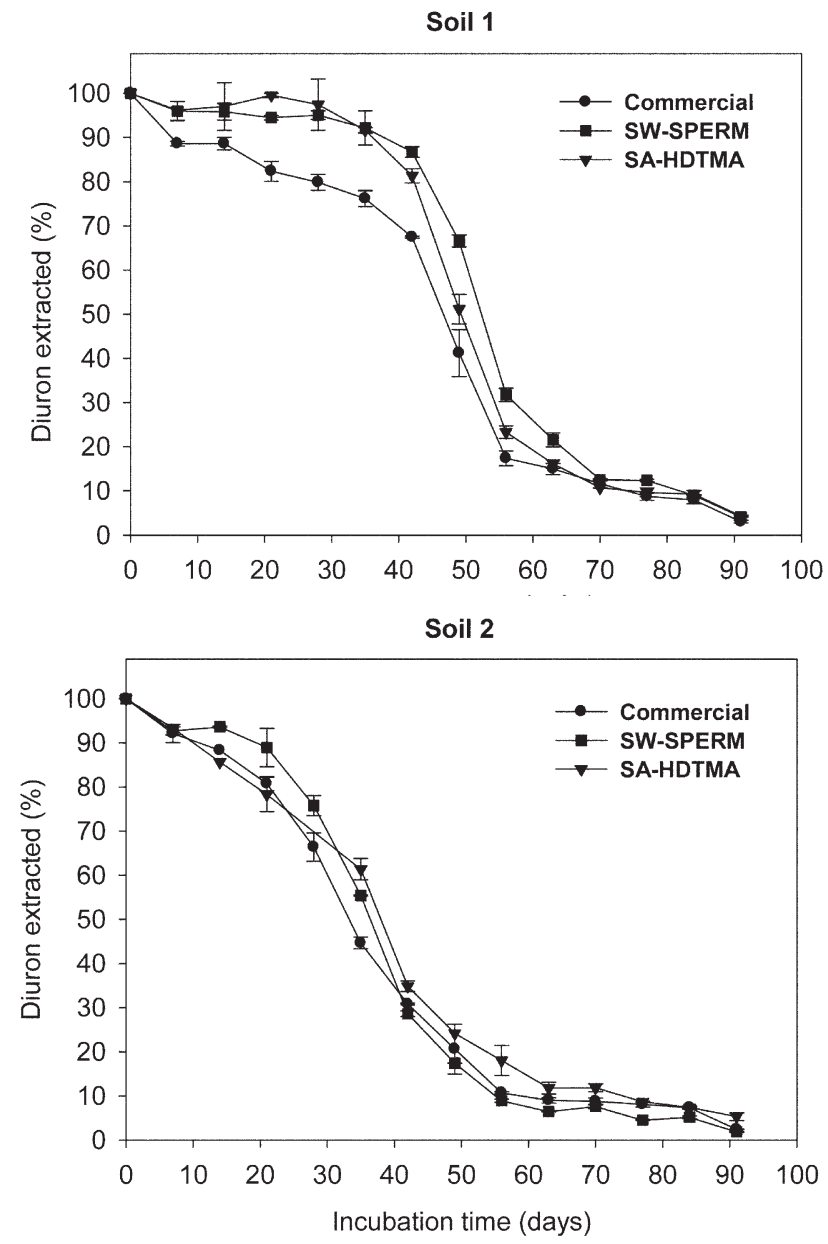

Fig. 4. Dissipation curves for diuron applied to soils as commercial and organoclay-based formulations. 
Soil 1
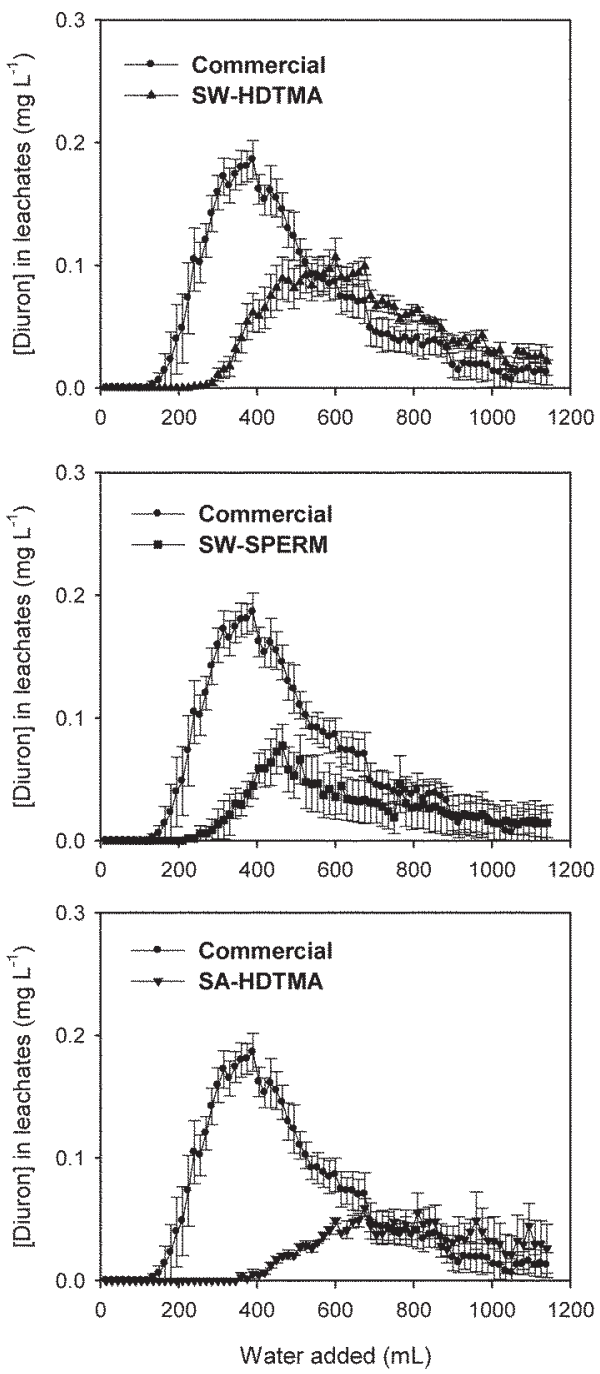

Soil 2
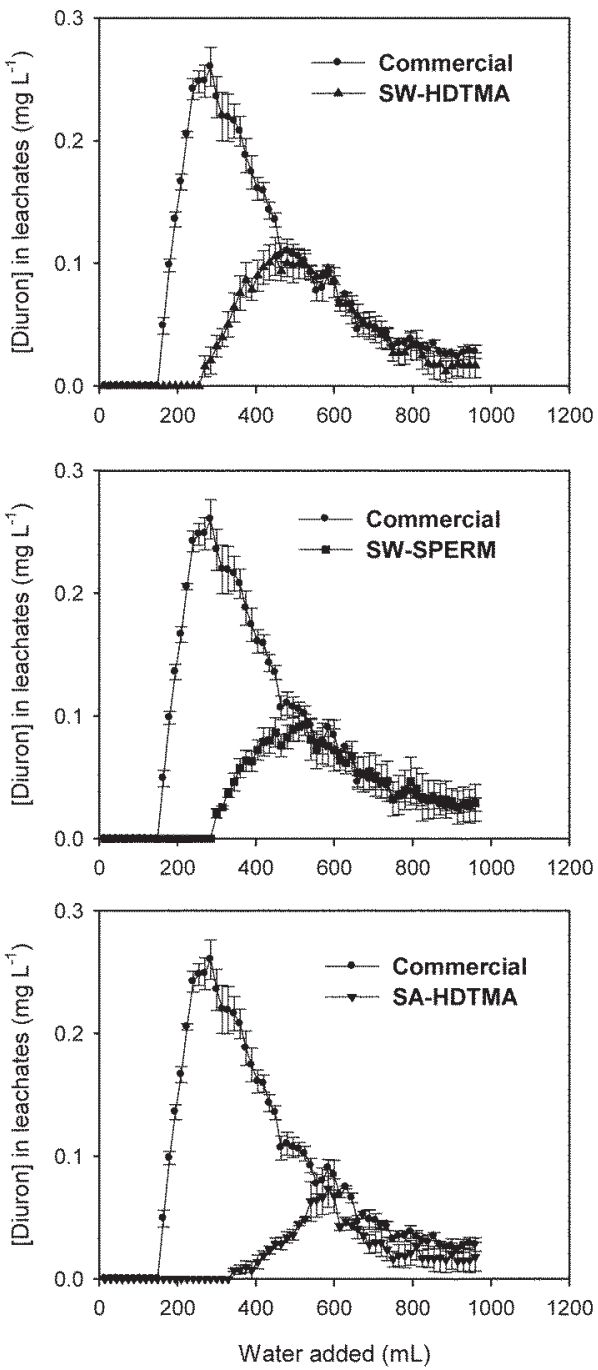

Fig. 5. Breakthrough curves (BTCs) of diuron applied to soil columns, soil 1 (left) and soil 2 (right), as commercial and organoclay-based formulations.

\section{Column Leaching Experiment}

Breakthrough curves (BTCs) of diuron applied to soil columns as the reference standard commercial formulation and as organoclay-based formulations are shown in Fig. 5. For both soils, the application of diuron as organoclay-based formulations resulted in lower herbicide concentrations in leachates, flattening of the BTCs, and shifting of the maximum concentration peak to larger volumes of water added as compared with the standard commercial formulation (Fig. 5). The total amount of diuron leached from the soil columns were also significantly reduced by the application of diuron as organoclay formulations (Table 4). In general, these effects were more pronounced for SA-HDTMA and SW-SPERM than for SW-HDTMA, which is in accordance with the adsorption and release behavior observed in the batch experiments (Fig. 2 and 3).

Leaching of diuron through Soil 2 occurred faster and with greater leachate concentrations than through Soil 1, particularly when the herbicide was applied as standard commercial formulation (Fig. 5). The low organic matter content and coarse texture of Soil 2 (Table 1) should have resulted in reduced retention of the herbicide by this soil, thus favoring leaching. Rapid leaching of diuron through Soil 2 can explain that the amounts of diuron extracted from the soil columns at the end of the leaching experiment were small compared with Soil 1 (Table 4, Fig. 6). Nonetheless, the shorter persistence of the herbicide in Soil 2 (Fig. 4) could have also contributed to the low residual amounts of diuron found in this soil.

The amount of diuron not recovered during the column leaching experiment (Table 4) can be attributed to degradation of the herbicide within the soil column and/or to irreversible adsorption to the soil or organoclay particles, but taking into account the duration of the column leaching experiment (64-76 d) and the dissipation patterns of diuron (Fig. 4), we believe that much of the herbicide not recovered should correspond to herbicide degraded within the soil column. It is interesting to note that, assuming the amounts not recovered (Table 4) being due to degradation of diuron during the leaching experiment, degradation of the herbicide within the soil columns was in general enhanced by the use of the organoclay formulations. Presumably, the slow release of diuron from the organoclays increased the residence time of the herbicide within the soil column, favoring its degradation.

\section{CONCLUSIONS}

Batch, incubation, and column leaching tests were designed to characterize the release, persistence, and mobility of organoclay-based formulations of the herbicide diuron in two Spanish soils dedicated to olive growing. The organoclay-based formula-

Table 4. Total amounts of diuron leached, extracted from the soil columns, and not recovered at the end of the leaching experiment and maximum herbicide concentration found in leachates.

\begin{tabular}{|c|c|c|c|c|c|c|c|c|}
\hline \multirow[b]{2}{*}{ Formulation } & \multicolumn{4}{|c|}{ Soil 1} & \multicolumn{4}{|c|}{ Soil 2} \\
\hline & Commercial & SW-SPERM & SW-HDTMA & SA-HDTMA & Commercial & SW-SPERM & SW-HDTMA & SA-HDTMA \\
\hline $\begin{array}{l}\text { Maximum } \\
\text { concentration, } \mathrm{mg} \mathrm{L}^{-1}\end{array}$ & $0.19 \pm 0.02 \dagger$ & $0.09 \pm 0.02$ & $0.11 \pm 0.02$ & $0.06 \pm 0.01$ & $0.26 \pm 0.02$ & $0.09 \pm 0.01$ & $0.11 \pm 0.02$ & $0.07 \pm 0.02$ \\
\hline Leached, \% & $42 \pm 5$ & $16 \pm 8$ & $28 \pm 3$ & $15 \pm 4$ & $52 \pm 1$ & $22 \pm 1$ & $24 \pm 1$ & $11 \pm 1$ \\
\hline Extracted from soil, \% & $14 \pm 5$ & $20 \pm 8$ & $27 \pm 5$ & $25 \pm 1$ & $10 \pm 1$ & $10 \pm 2$ & $5 \pm 3$ & $7 \pm 5$ \\
\hline Not recovered, \% & 44 & 64 & 45 & 60 & 38 & 68 & 71 & 82 \\
\hline
\end{tabular}

† Mean \pm standard error. 
Soil 1
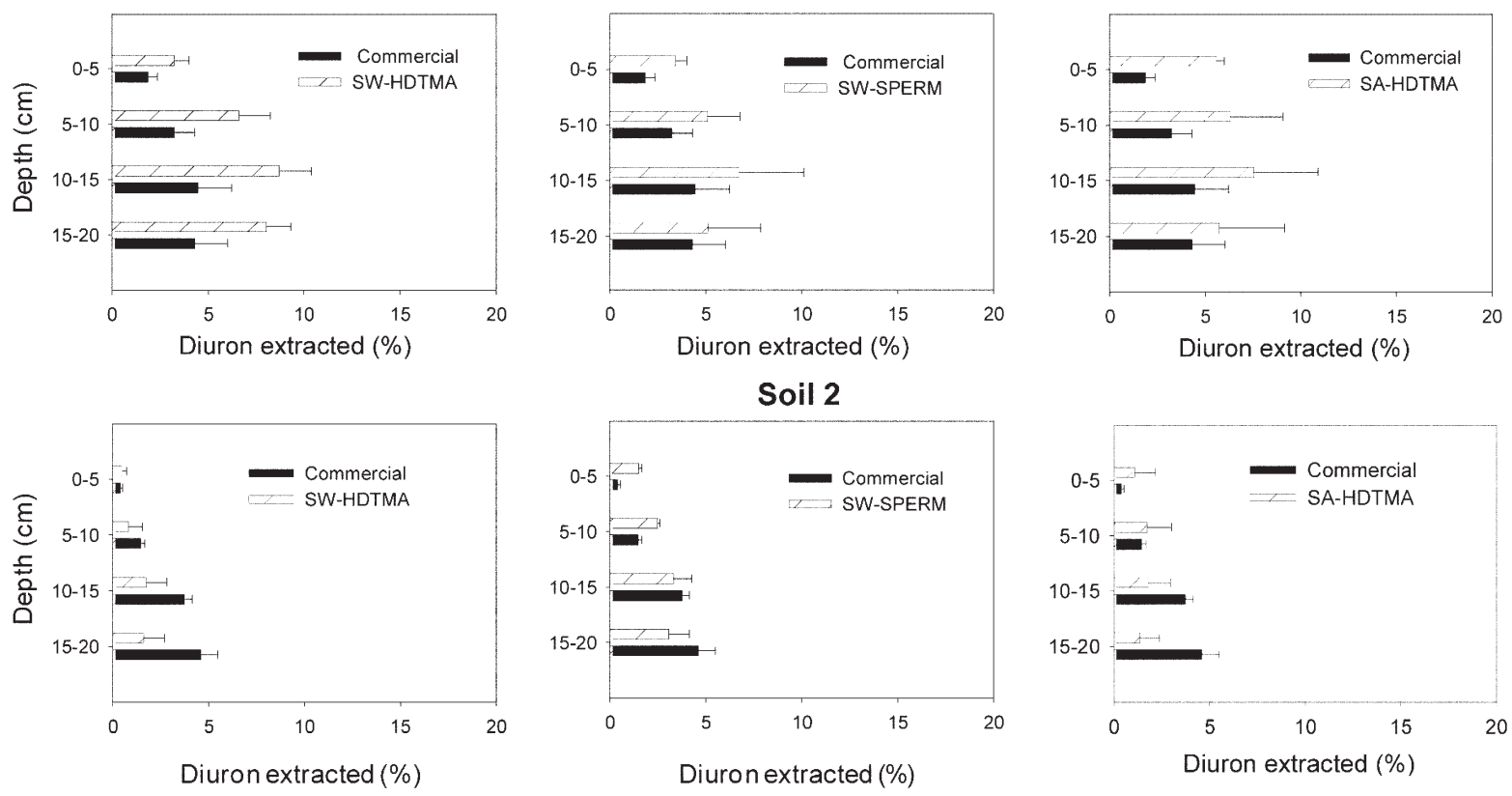

Fig. 6. Diuron extracted from different depths of the soil columns at the end of the leaching experiment.

tions of the herbicide were effective in retarding the release of the herbicide into aqueous solution, thereby reducing the leaching of the herbicide through the soils, compared with a standard commercial formulation containing the herbicide in a readily available form. Incubation experiments indicated that the dissipation pattern of diuron in the soils for the herbicide applied as organoclay-based formulations was very similar to that of the herbicide applied in the commercial form, and that most of the herbicide in the formulations was ultimately available for degradation. The results indicate that organoclay-based formulations can be useful to reduce extensive transport losses associated with the application of diuron in high-risk scenarios, such as Mediterranean olive groves, with little effect on its degradation pattern. Additional research would be needed to demonstrate that the bioavailability of diuron in these formulations is high enough to achieve adequate weed control and to demonstrate if their performance under real field conditions matches the potential shown in the laboratory.

\section{ACKNOWLEDGMENTS}

This work has been financed by the Spanish Ministry of Education and Science, with FEDER funds, through the projects AGL2005-05063-C02-01 and AGL2008-04031-C02-01. C. Trigo also thanks the Spanish Ministry of Education and Science for her FPI fellowship (ref. BES-2006-14099).

\section{REFERENCES}

Barriuso, E., W.C. Koskinen, and M.J. Sadowsky. 2004. Solvent extraction characterization of bioavailability of atrazine residues in soils. J. Agric. Food Chem. 52:6552-6556.

Brinch, U.C., F. Ekelund, and C.S. Jacobsen. 2002. Method for spiking soil samples with organic compounds. Appl. Environ. Microbiol. 68:1808-1816.

Carrizosa, M.J., M.C. Hermosín, W.C. Koskinen, and J. Cornejo. 2003. Use of organosmectites to reduce leaching losses of acidic herbicides. Soil Sci. Soc. Am. J. 67:511-517.

Celis, R., C. Trigo, G. Facenda, M.C. Hermosín, and J. Cornejo. 2007. Selective modification of clay minerals for the adsorption of herbicides widely used in olive groves. J. Agric. Food Chem. 55:6650-6658.

Chaplain, V., E. Barriuso, J.C. Dur, and C. Vergnet. 2001. Influence of the formulation on the sorption and the mobility of diuron in soil. Bull. Environ. Toxicol. 66:664-670.
Cornejo, L., R. Celis, C. Domínguez, M.C. Hermosín, and J. Cornejo. 2008. Use of modified montmorillonites to reduce herbicide leaching in sports turf surfaces: Laboratory and field experiments. Appl. Clay Sci. 42:284291.

Cotterill, J.V., R.M. Wilkins, and F.T. da Silva. 1996. Controlled release of diuron granules based on a lignin matrix system. J. Control. Release 40:133-142.

Cox, L., and A. Walker. 1999. Studies on time-dependent sorption of linuron and isoproturon in soils. Chemosphere 38:2707-2718.

Cruz-Guzmán, M., R. Celis, M.C. Hermosín, and J. Cornejo. 2004. Adsorption of the herbicide simazine by montmorillonite modified with natural organic cations. Environ. Sci. Technol. 38:180-186.

Cruz-Guzmán, M., R. Celis, M.C. Hermosín, W.C. Koskinen, and J. Cornejo. 2005. Adsorption of pesticides from water by functionalized organobentonites. J. Agric. Food Chem. 53:7502-7511.

El-Nahhal, Y., S. Nir, C. Serban, O. Rabinovitz, and B. Rubin. 2001. Organoclay formulation of acetochlor for reduced movement in soil. J. Agric. Food Chem. 49:5364-5371.

Fernández-Pérez, M., M. Villafranca-Sánchez, E. González-Pradas, and F. FloresCéspedes. 1999. Controlled release of diuron from an alginate-bentonite formulation: Water release kinetics and soil mobility study. J. Agric. Food Chem. 47:791-798.

Gerstl, Z., A. Nasser, and U. Mingelgrin. 1998. Controlled release of pesticides into soils from clay-polymer formulations. J. Agric. Food Chem. 46:3797-3802.

Giacomazzi, S., and N. Cochet. 2004. Environmental impact of diuron transformation: A review. Chemosphere 56:1021-1032.

Hance, R.J., P.D. Smith, and E.G. Cotterill. 1977. The effect of age on the availability of linuron and simazine residues in soil. Weed Res. 17:429-431.

Hermosín, M.C., M.J. Calderón, J.P. Aguer, and J. Cornejo. 2001. Organoclays for controlled release of the herbicide fenuron. Pest Manag. Sci. 57:803-809.

Jaynes, W.F., and S.A. Boyd. 1991. Clay mineral type and organic compound sorption by hexadecyltrimethylammonium exchanged clays. Soil Sci. Soc. Am. J. 55:43-48.

Kearney, P.C., D.R. Shelton, and W.C. Koskinen. 1997. Soil chemistry of pesticides. p. 419-451. In M. Howe-Grant (ed.) Encyclopedia of chemical technology. 4th ed. Vol. 22. John Wiley \& Sons, New York.

Lagaly, G. 2001. Pesticide-clay interactions and formulations. Appl. Clay Sci. 18:205-209.

Prost, R., and B. Yaron. 2001. Use of modified clays for controlling soil environmental quality. Soil Sci. 166:880-895.

Santiago-Mora, R., F. Martin-Laurent, R. De Prado, and A.R. Franco. 2005. Degradation of simazine by microorganisms isolated from soils of Spanish olive fields. Pest Manag. Sci. 61:917-921.

Worthing, C.R., and R.J. Hance. 1991. The pesticide manual. British Crop Protection Council, Surrey, UK. 